\title{
INTERFACE, DENOTAÇÃO, CONOTAÇÃO E PROSÓDIA SEMÂNTICA. APORTAÇÕES LINGUÍSTICAS PARA OS ESTUDOS DE TRADUÇÃO
}

Pedro Guilherme (UBI, PT)

Paulo Osório (UBI, PT)

Resumo: O exercício da tradução implica que todos os níveis funcionais de uma língua, bem como todas as relações entre os seus constituintes, sejam tomados em consideração. As sequências discursivas das línguas - original e de destino - devem ser abordadas de um modo sistemático e que inclua também realidades extratexto. Por esse motivo, a Prosódia Semântica, que resulta das inter-relações entre os diferentes níveis funcionais, deverá ser tomada em linha de conta, principalmente porque é passível de introduzir no discurso valores semânticos e pragmáticos muitas vezes distintos da própria intenção comunicativa do autor, a qual deverá ser replicada na língua de destino.

Palavras-chave: tradução, denotação, conotação, prosódia semântica.

Abstract: The act of translation requires that all the functional levels of a given language, as well as the relations among its elements, be taken into account. Discourse sequences of both original and target languages should be dealt with in a systematic manner that further incorporates extratextual realities. Thus, Semantic Prosody, which results from the relations among all functional levels, should be taken into consideration, mainly because it is likely to trigger, in the discourse, semantic and pragmatic values that may differ from the very author's communicative intent, which should be replicated in the target language.

Keywords: translation, denotation, connotation, semantic prosody.

\section{INTRODUÇÃO}

Qualquer tradução requer a análise de uma sequência discursiva, a qual se dá a várias instâncias que, embora tenham 
como objecto elementos distintos, ocorrem em simultâneo e indissociavelmente. Logo, há que atender aos diferentes níveis funcionais que operam na sequência discursiva, sendo necessário recorrer às diferentes áreas dos estudos linguísticos, exceptuando-se, no caso da análise do texto escrito, a fonética e a fonologia. Embora o exercício da hermenêutica por parte do tradutor seja, numa primeira instância, um processo algo imediato - partindo-se, naturalmente, do princípio de que o tradutor detém alguns conhecimentos das línguas em que opera - este tem de ser levado a cabo de uma forma sistemática, que explanaremos adiante.

Ainda que as gramáticas e os dicionários sejam um recurso indispensável à tradução, a melhor resposta aos problemas que a utilização real da língua impõe será certamente a utilização dos corpora linguísticos. Assim como a zoologia requer experiências realizadas no campo (caso as variáveis sejam artificialmente limitadas, afigura-se impossível a obtenção de resultados fiáveis e concludentes), também a linguística precisa de abordar o seu objecto, tendo em conta uma dinâmica, que somente se processa na totalidade quando a língua age fora do "cativeiro" do dicionário; este, embora cada vez menos redutor $^{1}$, a coloca em contextos

1 Dicionários como o Cambridge Advanced Learner's Dictionary (Cambridge University Press, 2003) definem já algumas entradas lexicais, tomando em consideração a sua prosódia semântica. O referido dicionário define, por exemplo, notorious como "Famous for something bad". 
que poderão ser anacrónicos e, como tal, parcialmente desfasados da realidade.

\section{INTERFACES}

Torna-se, então, absolutamente necessária a utilização das diferentes ciências linguísticas, tomando em linha de conta a sua interface. É nossa opinião que o conceito de interface parta da sintagmática, uma vez que se torna mais simples distribuir e interpretar as diferentes funções, bem como os níveis funcionais que os elementos desempenham ao longo da sequência discursiva e, por conseguinte, associar os elementos sob escopo a uma ou mais ciências linguísticas.

Embora a sintagmática se subdivida em dois grandes grupos, os elementos abordados (monema e sintagma para a sintagmémica, sintagma e enunciado para a sintaxe oracional, enunciado e texto no caso da sintaxe de enunciados) desempenham uma relação de interdependência, influenciando-se mutuamente no que diz respeito aos níveis funcionais sintáctico, semântico e informativo. Todavia, a teia de inter-relações entre os elementos só se torna completa quando se coloca em evidência a presença da Prosódia Semântica². Antes, porém, que alarguemos

2 Fenómeno léxico-gramatical que ocorre quando determinados itens lexicais, por associação repetida (co-ocorrência) a determinados contextos, positivos ou negativos, sofrem uma alteração dos seus valores semântico e/ou pragmático. À significação que esses itens lexicais adquirem por coocorrência, propomos que se chame carga parasemântica. Logo, um item lexical 
as nossas considerações acerca deste subnível funcional, torna-se pertinente explicitar a relação entre sintagmática, lexicologia, morfologia, semântica e pragmática.

No que diz respeito à lexicologia, esta só é aplicada quando se abordam como unidades mínima e máxima o monema e o lexema, respectivamente. Naturalmente, a abordagem de um lexema não descarta a compreensão da sua componente semântica, partindo-se do sentido denotativo. Já a conotação, embora determinada com mais precisão aquando da inclusão da unidade lexical na sequência discursiva, poderá ser parcialmente reconhecida, ou pelo menos deduzida, observando-se a concatenação dos monemas. Se ao monema livre "homem" estiver aglutinado o monema "-inho" (juntamente com a consoante de ligação /z/), pode já propor-se uma alteração da informação semântica no que diz respeito à conotação. Neste sentido, pode já compreender-se a estreita ligação que existe entre a lexicologia e a morfologia derivacional. O processo de afixação que se dá neste caso poderá ser uma parcela importante se, num passo posterior se analisar o texto entretecendo-se os planos intrasintagmático e intersintagmático. Naturalmente, a semântica é uma ciência que, estudando o segundo nível funcional de uma sequência discursiva, o qual subjaz a todos

que tenha adquirido carga parasemântica é passível de desencadear Prosódia Semântica. 
os elementos que a compõem, conforme demonstrado, pode ser aplicada ao estudo do monema como unidade mínima do texto escrito, possuindo significante e significado.

A pragmática será já uma ciência que somente adquire verdadeira importância quando os lexemas se ligam, desempenhando funções distintas que irão formar a sequência discursiva. No entanto, para se reconhecer o nível funcional informativo, o discurso não pode ser abordado como um gestalt, mas sim como possuindo constituintes imediatos e mediatos que o irão formar. Em termos de significado, será a informação semântica de cada elemento o que nos oferecerá o sentido do discurso. Porém, a aplicação de semantemas, bem como a sua concatenação, não constitui linearmente um significado, pelo que é muitas vezes necessário que se recorra a conhecimentos além-texto. O tradutor, perante it's raining cats and dogs, não só precisa de analisar sintáctica, morfológica e semanticamente esta sequência discursiva, mas também tem de a associar ao texto em que se inclui e a um mundo possível, enunciado por Eco (2005, pp. 172, 173) ao descrever exercícios de retroversão que lhe permitissem descortinar a razão de incoerências em traduções que revia:

... [Na] tradução de um livro de psicologia, deparou-se-me que, no decorrer de uma 
experiência, a abelha [em italiano: I'ape] conseguiu apanhar a banana posta fora da sua jaula com a ajuda de um pau. [...] Era claro que o original falava de um ape, ou seja, de um chimpanzé, e o meu conhecimento do mundo [...] diziame que os macacos apanham e comem bananas [...] [Fiz] algumas inferências sobre o mundo possível descrito [...] presumivelmente afim ou idêntico ao mundo que vivemos - e tentei imaginar como se comportariam [...] abelhas.

Observe-se, então, como o frasema inglês poderá ser processado:

\begin{tabular}{|c|c|c|c|c|c|c|c|c|}
\hline \multicolumn{2}{|c|}{ It's } & \multirow{2}{*}{\multicolumn{2}{|c|}{$\begin{array}{l}\text { raining } \\
\text { raining }\end{array}$}} & \multirow{2}{*}{\multicolumn{2}{|c|}{$\begin{array}{l}\text { Cats } \\
\text { Cats }\end{array}$}} & and & \multirow{2}{*}{\multicolumn{2}{|c|}{$\begin{array}{l}\text { dogs } \\
\text { dogs }\end{array}$}} \\
\hline It & is & & & & & and & & \\
\hline It & is & rain & -ing & Cat & $-s$ & and & Dog & $-s$ \\
\hline $\begin{array}{c}\text { Monema } \\
\text { pronominal } \\
\text { "it" }\end{array}$ & $\begin{array}{l}\text { Monema } \\
\text { verbal "is" }\end{array}$ & $\begin{array}{l}\text { Monem } \\
\text { a verbal } \\
\text { "rain" }\end{array}$ & $\begin{array}{l}\text { Monema } \\
\text { <gerúndio> }\end{array}$ & $\begin{array}{c}\text { Monema } \\
\text { verbal } \\
\text { "cat" }\end{array}$ & $\begin{array}{l}\text { Monema } \\
<\text { plural > }\end{array}$ & $\begin{array}{l}\text { Monema } \\
\text { "and" }\end{array}$ & $\begin{array}{c}\text { Monema } \\
\text { verbal } \\
\text { "dog" }\end{array}$ & $\begin{array}{l}\text { Monema } \\
\text { <plural> }\end{array}$ \\
\hline F1 (sujeito) & \multicolumn{3}{|c|}{ Predicado } & \multicolumn{5}{|c|}{ F2 (complemento directo) } \\
\hline Pronome & Verbo & \multicolumn{2}{|c|}{ verbo } & \multicolumn{2}{|c|}{ substantivo plural } & $\begin{array}{l}\text { conjunção } \\
\text { copulativa }\end{array}$ & \multicolumn{2}{|c|}{$\begin{array}{c}\text { Substantivo } \\
\text { masculino plural }\end{array}$} \\
\hline Núcleo ora & $\begin{array}{l}\text { onal no Part } \\
\text { principal in }\end{array}$ & $\begin{array}{l}\text { cípio Pres } \\
\text { npessoal }\end{array}$ & nte e verbo & & & & & \\
\hline
\end{tabular}

Tendo em conta tanto a decomposição da sequência discursiva em unidades mínimas significativas, como a atribuição de classes morfológicas aos lexemas (ou, como ocorre com o núcleo oracional, conjunto de unidades lexicais) de funções sintácticas às orações e de funções 
semânticas a cada oração e seus constituintes, seria de esperar, em termos de análise linear e imanente, que a tradução resultante fosse está a chover cães e gatos (elidindo-se o monema <gerúndio> tendo em conta o desuso, no português europeu, desta forma nominal em orações subordinantes). Todavia, na maioria dos casos, não será esse o resultado da tradução. O tradutor, ao interpretar a sequência discursiva, não irá, decerto, cingirse exclusivamente à soma dos traços semânticos de cada unidade, compreendendo que se encontra perante uma expressão idiomática e traduzindo-a de acordo com a informação que o meio social de ambas as línguas oferece. Nestes casos, os traços semânticos constituem um degrau para a percepção do nível informativo. Este fenómeno será ainda mais visível quando um determinado elemento for analisado não só no plano intrasintagmático, mas também no plano intersintagmático. Esta última análise não significa uma abordagem em que a unidade mínima é o sintagma ou o enunciado e a máxima é o texto. A unidade mínima pode encontrar-se em qualquer posição hierárquica, bem como a unidade máxima (obviamente, a posição terá de ser superior à da unidade mínima estudada). Isto porque, sendo a informação semântica subjacente ou repartida pela sequência discursiva, é premente interrelacionar-se os 
traços de um elemento com os de outro, independentemente da sua hierarquia.

Isso significa que o recurso aos corpora, ainda que valioso, não descarta naturalmente o conhecimento da totalidade do texto já que, apesar de se identificarem traços semânticos - e de Prosódia Semântica - em segmentos de hierarquia tão baixa como o monema, o lexema ou o sintagma, será a pragmática, subjacente ou não ao texto, a ditar a conotação de um determinado item lexical e vice-versa. Isto porque tanto a Prosódia Semântica criada pelo item lexical influencia a carga pragmática dos segmentos em que se insere ou da totalidade do texto como a pragmática poderá transformar a carga parasemântica (ou seja, a significação adquirida por co-ocorrências habituais de um lexema que desencadeia Prosódia Semântica) em sentido conotativo. Imaginemos que nos encontramos perante a seguinte frase: O homem cometeu acções de caridade ao longo da sua vida. Imediatamente, o alocutário desta mensagem é acometido por uma sensação de estranheza. Embora cometer seja um verbo que indique a realização de uma determinada acção, sabe intuitivamente que a acção levada a cabo é má. Todavia, a estranheza esvai-se caso se verifique que o texto em que esta frase se insere é de cariz irónico ou satírico. Poderia, por 
exemplo, falar-se de um indivíduo egoísta e arrogante que apenas simulava a sua filantropia para obter mais atenção dos outros. Neste caso, a pragmática do texto não deixaria que, no eixo paradigmático, «cometeu», por exemplo, coexistisse com "praticou» como unidade discreta, passando a Prosódia Semântica da frase isolada a mero sentido conotativo ou até, tendo em conta a clareza do texto no concernente à animosidade face ao sujeito, sentido denotativo. Logo, verifica-se existir uma interdependência entre os três níveis funcionais da sequência discursiva. Se a disposição das unidades na sequência determinam a sua carga semântica e pragmática, também a semântica impõe restrições combinatórias nos eixos sintagmático ou paradigmático, a qual será, por sua vez, constituinte dos traços pragmáticos. Caso a intenção comunicativa seja, por exemplo, de fazer um pedido delicado, os traços pragmáticos que se pretendem desenvolver requerem um registo cuidado. Suponhamos, neste sentido, a sequência discursiva «Dá-me os papéis». Em termos de registo, estamos perante um enunciado cuja carga pragmática é neutral. F1 e predicado contraem-se no verbo (modo imperativo) e F2 é preenchida por um simples artigo definido plural e um substantivo plural. Todavia, um pedido mais delicado requer já, por exemplo, o modificador «por favor». Por outro lado, um registo menos delicado excluirá 
este modificador em prol de interjeições e/ou expressões de qualificação, bem como de signos enunciativos:

Dá(s)-me os papéis.(!/?)

Dá(s)-me a porcaria dos papéis.(!/?)

Raios, dá(s)-me os papéis.(!/?)

Raios, dá(s)-me a porcaria dos papéis.(!/?)

Em termos combinatórios, não se pode já entender que, aposto ao segundo exemplo (e ao primeiro), o modificador «por favor» indique um registo delicado, mas sim uma expressão que enfatize o enunciado. Nos casos em que se verifica presença da interjeição «raios», o modificador «por favor» não pode coexistir no eixo sintagmático. Concluímos, então, que:

a) a disposição sintáctica determina as cargas semântica e pragmática;

b) há restrições combinatórias no que diz respeito a funções semânticas, tendo em conta os níveis sintáctico e pragmático do discurso;

c) uma determinada intenção comunicativa (pragmática) restringe a disposição sintáctica de determinadas unidades e, simultaneamente, a coexistência de dois semantemas opostos, podendo ocorrer, em alguns casos, omissão e truncagem. 
Naturalmente, estas conclusões não podem ser compreendidas como regras absolutas, uma vez que se aplicam somente a casos análogos ao exemplo apresentado. No entanto, esta separação poderá não ser tão clara no caso de haver lexemas passíveis de originar Prosódia Semântica. No caso do lema cometer, bem como da suposta Prosódia Semântica que desencadeia quando violado o seu sentido conotativo, as restrições combinatórias prendem-se mormente à semântica:

Conforme se pode observar, a comutação entre unidades discretas ao longo da sequência discursiva não impõe já uma alteração da distribuição das propriedades sintácticas e morfológicas. Em «Ele cometeu uma boa acção», temos, em termos morfológicos, um pronome pessoal masculino singular, um verbo transitivo, um artigo definido feminino singular, um adjectivo feminino singular e um substantivo. Sintacticamente, dispõem-se por ordem F1, núcleo oracional e F2. Comutando «cometeu» com "praticou», ou «má» com «boa», tanto as classes morfológicas como as funções sintácticas se mantêm inalteradas, ou seja, os functivos disponíveis são sempre preenchidos pelos mesmos functemas. Assim, as restrições combinatórias apresentadas aquando da comutação são principalmente 
de ordem semântica, pertencendo as sintácticas a questões de concordância. Note-se também que, neste caso, acção e objecto se relacionam por, respectivamente, um verbo e um adjectivo, os quais funcionam numa relação de dependência em termos sintagmáticos: o lexema verbal «cometeu» não pode, em termos sintácticos, coexistir com o lexema adjectival «boa», ao passo que «praticou» é compatível com

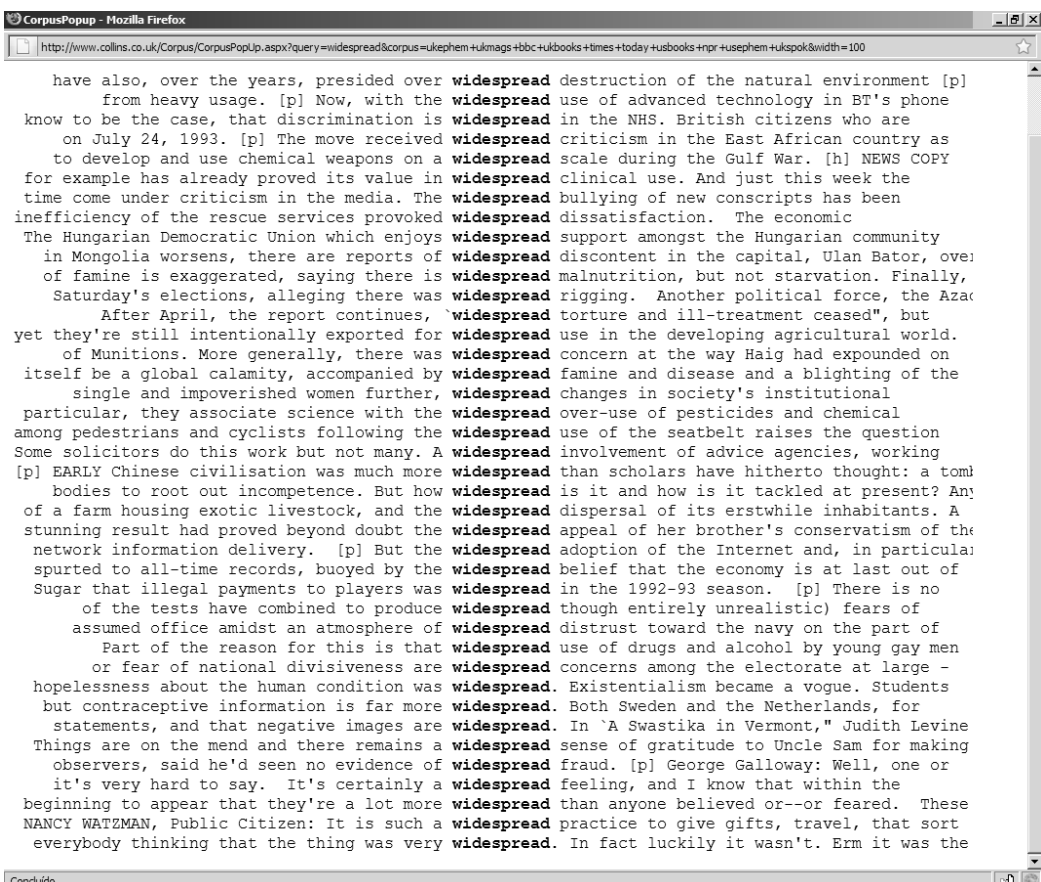

Resultados de widespread no Bank of English

Neste caso, as únicas restrições que se podem impor dar-se-ão na tradução. O adjectivo widespread, não 3 Bank of English [online], Acedido em: Maio 16 2009, URL: http://www.collins.co.uk/corpus/ Corpus Search.aspx. 
possuindo uma conotação negativa (para além de possuir co-ocorrentes como «destruction», «discrimination», «bullying», «dissatisfaction», «discontent» e «torture», entre outros, é também adstrito a casos positivos ou, pelo menos, neutrais à primeira vista como "sense of gratitude») pode ser aposto a mais co-ocorrentes. Tendo em conta este facto, é já mais difícil encontrar um quase-sinónimo que corresponda, em português, ao negativismo semântico deste lexema adjectival. Propomos, por exemplo, para situações de Prosódia Semântica negativa, o adjectivo disseminado em oposição a generalizado.

Não obstante o lexema desencadear Prosódia Semântica, a subtileza que reside no seu significado (alterado seja por comunidades de falantes e/ou por questões de ordem diacrónica) não apresenta terminais tão selectivos como ocorre no caso dos lemas/semas cometer ou commit. Assim, será o volume de restrições combinatórias no respeitante ao semantema abordado a determinar as suas propriedades conotativas. Concluímos, desse modo, que cometer pode, no máximo, possuir um mero sentido conotativo verificado de uma forma quase acrítica. Denotação, conotação e Prosódia Semântica operam sempre nos traços pragmáticos da sequência discursiva que constituem, ocorrendo também o 
contrário. Todavia, a apropriação do conteúdo informativo final obtém-se mediante graus de dificuldade respectivos ao tipo de carga semântica que os lexemas apresentam. Logo, o autor do texto original pode, conscientemente ou não, munir-se de semantemas que tornem a percepção dos traços pragmáticos do discurso mais sensível ao conhecimento, intuitivo ou científico, da língua em questão. O facto é que, estando dependente da semântica e da pragmática do discurso que constitui, a definição de Prosódia Semântica encontra-se entre a pragmática e a semântica, dividida em sentidos denotativo e conotativo.

Temos, até agora, abordado casos de esquemas sintagmáticos verbais. Contudo, é premente afirmar-se que, por combinação ou oposição de unidades discretas, a estrutura sintáctica de sequências discursivas com diferentes esquemas sintagmáticos se mantém, bem como a presença de F1, predicado e, quando aplicável, F2, F3 (complemento indirecto) e F4 (complemento circunstancial), ainda que, muitas vezes, subentendidos e/ou amalgamados. Os functivos adstritos a um determinado functema requerem sempre, aquando da comutação por unidades discretas, preenchimento por funções análogas às activas no eixo sintagmático. É também possível que determinadas 
sequências discursivas não admitam um grande volume de comutações. Para casos como "Lindo serviço!», a presença de unidades discretas é muito restrita, uma vez que lidamos com uma expressão idiomática, cujo esquema sintagmático é adjectival, e que possui um sentido sarcástico ou de crítica. Assim, em prol dos traços pragmáticos, as restrições combinatórias são escassas, havendo somente a hipótese de se comutar «lindo» por adjectivos como «belo» ou "bonito». Mesmo que se decomponham os functivos preenchidos por F1, predicado e F2 (em Tu [F1] fizeste [predicado] um lindo serviço [F2]! [signo enunciativo], por exemplo), as possibilidades combinatórias dar-se-ão somente nos campos de F1, predicado e signo enunciativo. Assim, o nível informativo rege a combinação sintáctica e semântica da sequência discursiva em que se manifesta.

Logo, o tradutor, ao abordar uma determinada sequência linguística, terá obrigatoriamente de tomar em consideração o facto de todos os níveis funcionais serem interdependentes. Nenhum dos níveis se manifesta sem a presença e influência dos restantes, pelo que as análises lexicológica, morfológica, sintáctica, semântica e pragmática não se processam linearmente, mas sim em constante sinergia, posta a constante actualização que exercem sobre a sequência discursiva. 
O processo de tradução requer que não apenas se tome em linha de conta a complexa estrutura da sequência discursiva, mas também a sua inegável componente social. Esta, enquanto não verificada directamente na sequência discursiva, e que não só se manifesta na denotação e na conotação mas também, de forma mais sub-reptícia, na Prosódia Semântica, tem de ser identificada, circunscrita e correctamente actualizada aquando da tradução. No que diz respeito aos tipos de tradução possíveis, e correspondente resposta às manifestações semânticas e informativas presentes no texto-fonte, propomos as seguintes classificações:

\begin{tabular}{|c|c|c|}
\hline 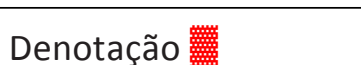 & 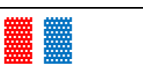 & Tradução literal \\
\hline 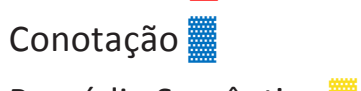 & 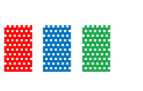 & $\begin{array}{l}\text { Tradução ponderada } \\
\text { contextualizada translúcida }\end{array}$ \\
\hline 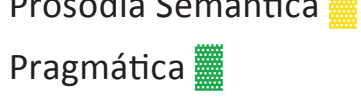 & & $\begin{array}{l}\text { Tradução ponderada } \\
\text { contextualizada transparente }\end{array}$ \\
\hline
\end{tabular}

\section{CONCLUSÃO}

A pragmática referida neste quadro trata-se de uma percepção não imanente e que toma em consideração os reflexos da polis no texto original. A tradução literal será unicamente uma solução correcta caso o tradutor lide com um texto de cariz científico e cujas asserções se verifiquem através de uma análise semântica mais superficial. Todavia, a 
tradução ponderada contextualizada translúcida relacionará o texto com a intenção comunicativa do autor de um ponto de vista mais objectivo, visto que a apropriação dos conceitos desenvolvidos é levada a cabo como um acordo entre o autor e a comunidade de falantes ou, mais particularmente, o leque de leitores-modelo.

A tradução aproxima-se, todavia, mais da transparência (não se pode alguma vez garantir uma transparência plena quando se fala de tradução, já que há sempre perdas irrecuperáveis, pelo menos parcialmente) quando a Prosódia Semântica desencadeada pelos lexemas é inserida na equação e vista como produto e/ou modificador da intenção comunicativa do autor do texto original. Somente desta forma é possível que o "movimento hermenêutico" (Steiner, 1998, pp. 312-317) enunciado por Steiner (confiança, agressão, incorporação e retribuição) ocorra na totalidade. Enquanto a confiança e a incorporação são passos pertencentes à tradução literal, a tradução ponderada contextualizada translúcida passa já, para além dos passos enunciados, pela agressão. No entanto, as instâncias de confiança, agressão, incorporação e retribuição só se tornam possíveis no terceiro tipo de tradução por nós enunciado. Note-se também que a forma, ou a componente sintáctica do discurso original tem, 
por vezes, de ser reproduzida da melhor maneira possível. Será caso disso, por exemplo, a tradução de um poema, em que a estrutura formal e a métrica devem também ser conservadas, sob pena de, caso contrário, se perder o ritmo e a musicalidade.

\section{REFERÊNCIAS}

Cambridge University Press. (2003). Cambridge Advanced Learner's Dictionary.

Eco, U. (2005). Dizer Quase a Mesma Coisa - Sobre a Tradução. Algés: Difel. HarperCollins. (s.d.). Bank of English. Obtido em 16 de Maio de 2009, de http://www.collins.co.uk/corpus/CorpusSearch.aspx

Steiner, G. (1998). After Babel: Aspects of Language and Translations. Oxford: Oxford University Press.

Paulo Osório é licenciado pela Universidade Católica Portuguesa, mestre pela Faculdade de Letras da Universidade de Coimbra, doutor e agregado pela Universidade da Beira Interior. É pós-doutor pela PUC-Rio. É Professor Associado com Agregação no Departamento de Letras da Universidade da Beira Interior (Covilhã, Portugal). É pesquisador do LabCom.IFP. Tem proferido inúmeras conferências em Portugal e no estrangeiro e publica, regularmente, em revistas da especialidade. Contacto: pjtrso@ubi.pt

Pedro Guilherme é licenciado, mestre e doutor pela Universidade da Beira Interior. É Professor do Laboratório de Línguas da Universidade da Beira Interior (Covilhã, Portugal). É pesquisador do LabCom.IFP. Publica em revistas da especialidade. Contacto: pmguilherme@portugalmail.com 